\title{
Discharge Destination from a Rehabilitation Unit After Acute Ischemic Stroke
}

\author{
Amalie Saab, Shiona Glass-Kaastra, Gordon Bryan Young
}

\begin{abstract}
Background: We reviewed numerous variables for ischemic stroke patients admitted to a rehabilitation unit to determine those that were statistically associated with discharge destination. Methods: A retrospective chart review of patients with ischemic stroke discharged from the rehabilitation unit between January 1, 2005 and December 31, 2015. Variables were examined for their association with discharge destination (home versus long-term care (LTC)). Univariable relationships with discharge destination were assessed, and a multivariable logistic regression model was built. Results: Univariate predictors of discharge to LTC: advanced age, decreasing admission and discharge functional independence measure (FIM) scores, increasing change in FIM score from admission to discharge, dependency, residence outside of home before the stroke, absence of a caregiver, urinary and bowel incontinence, low Berg balance score at admission and discharge, low Montreal Cognitive Assessment scores, smoking, chronic heart failure, and an inability to transfer. Multivariable logistic regression: five factors remained significant predictors with LTC disposition: advanced age, bowel incontinence, residence outside of the home prior to stroke, right hemisphere site of the stroke, and absence of a caregiver. Conclusions: Several easily measured variables were significantly associated with discharge to LTC versus home following stroke rehabilitation.
\end{abstract}

RÉSUMÉ : Lieux de destination de patients ayant obtenu leur congé après avoir été admis dans une unité en réadaptation à la suite d'un AVC. Contexte : Nous avons passé en revue les multiples variables associés aux patients victimes d'un AVC admis dans une unité en réadaptation afin de déterminer celles étant statistiquement associées à leur lieu de destination suite à leur congé. Méthodes : Pour ce faire, nous avons effectué un examen rétrospectif des dossiers de patients victimes d'un AVC. Nous nous sommes ainsi intéressés à ceux ayant été soignés dans une unité en réadaptation du $1^{\text {er }}$ janvier 2005 au 31 décembre 2015 et ayant obtenu par la suite leur congé. Nos variables ont été analysées en fonction de leur association avec le lieu de destination des patients suivant leur congé, à savoir leur domicile ou une unité de soins de longue durée (USLD). En plus d'évaluer les relations entre des variables uniques et le lieu de destination des patients, nous avons aussi élaboré un modèle statistique de régression logistique à variables multiples. Résultats : Les variables uniques prédisant un séjour dans une USLD sont les suivantes : un âge avancé ; des scores en baisse à la MIF au moment de l'admission et du congé ; des modifications de plus en plus nombreuses aux scores de la MIF entre l'admission et le congé ; la dépendance à autrui ; résider ailleurs que chez soi avant l'AVC; l'absence d'un proche aidant ; être atteint d'incontinence urinaire et fécale ; obtenir de bas scores à l'échelle d'évaluation de l'équilibre de Berg au moment de l'admission et du congé ; obtenir de bas scores au Montreal Cognitive Assessment; le tabagisme ; l'insuffisance cardiaque chronique ; et finalement, l'impossibilité d'un transfert. En ce qui regarde la régression logistique à variables multiples, 5 d'entre elles ont pu prédire de façon notable la possibilité d'être dirigé vers une USLD : un âge avancé ; l'incontinence fécale ; résider ailleurs que chez soi avant l'AVC ; un AVC affectant l'hémisphère droit du cerveau ; et finalement, l'absence d'un proche aidant. Conclusions : Après un programme de réadaptation post-AVC et l'obtention d'un congé, plusieurs variables facilement mesurables ont pu être clairement associées aux cas de patients dirigés vers une USLD plutôt qu'à domicile.

Keywords: Stroke, Stroke rehabilitation

doi:10.1017/cjn.2018.386

Can J Neurol Sci. 2019; 46: 209-215

\section{INTRODUCTION}

It is estimated that 264,000 or $0.75 \%$ of the Canadian population are living with the effects of stroke. ${ }^{1}$ Ischemic strokes are 10 times more common than hemorrhagic strokes. ${ }^{2}$ Although hemorrhagic strokes have a higher mortality in the acute phase, it has been shown that outcomes of both hemorrhagic and ischemic strokes in patients discharged from a rehabilitation setting are similar. $^{3}$ It is established that early in-patient rehabilitation for stroke patients is associated with improvement, better outcomes, and a higher percentage who return home. ${ }^{4-8}$ However, some patients are more likely to benefit than others; to maximize the use of scarce and expensive resources, some stratification and selection of patients are necessary.

From the Western University, London, Ontario, Canada (AS); Public Health Agency of Canada, Ottawa, Canada (SG-K); Grey Bruce Health Services, Owen Sound, Ontario, Canada (GBY).

Received May 5, 2018. Final Revisions Submitted November 6, 2018. Date of ACCEPtAnce November 27, 2018.

Correspondence to: G. Bryan Young, Grey Bruce Health Services, 1800-8th Street East, Owen Sound, Ontario N4K 6M9, Canada. Email: gyoung@gbhs.on.ca 
The functional independence measure (FIM) is an 18-item assessment of physical, psychological, and social functioning. The AlphaFIM, introduced in 2014 in Ontario, is more specifically designed for indices of stroke severity (using eating, grooming, bowel management, toilet transfers, expression, and memory) while patients are in the acute stroke units. ${ }^{3,9,10}$ In general, values between 40 and 80 for AlphaFIM are commonly used to select patients for rehabilitation: values above 80 can usually be managed in the community and values below 40 are often selected for "slow stream" rehabilitation or long-term care (LTC) from discharge from the acute stroke unit. ${ }^{9,11,12}$

Because of the higher incidence of ischemic stroke and since ischemic and hemorrhagic strokes often have different pathogeneses and comorbidities, we chose to study ischemic stroke patients who were admitted to our rehabilitation unit. ${ }^{13} \mathrm{We}$ selected patients admitted to our rehabilitation unit as there was a more comprehensive capture of variables than were obtained during the acute phase from referring hospitals.

The purpose of our study was to use a broad approach, weighing all the variables at our disposal to determine which were the most likely to be associated with transfer to LTC versus discharge home.

\section{Methods}

Records of all patients with acute ischemic stroke as the principal diagnosis who were discharged from our general rehabilitation unit at Grey Bruce Health Services in Owen Sound, Ontario, between January 1, 2005 and December 31, 2015 were reviewed and the following information was extracted: age at onset of stroke, sex, FIM, and AlphaFIM scores prior to admission and FIM scores at admission and at discharge from rehabilitation, difference in FIM between admission and discharge to rehabilitation. (FIM change), residence (living at home versus chronic care facility), independent activities of daily living, right versus left versus both cerebral hemispheres, bladder incontinence while in rehabilitation, bowel incontinence while in rehabilitation, dysphagia while in rehabilitation, aphasia, Berg Balance Scale score on admission and at discharge, change in Berg Balance Scale score from admission to discharge, ability to transfer at discharge, Montreal Cognitive Assessment (MoCA) score (done within 3 days of admission to rehabilitation), hemianopsia (assessed by a qualified neurologist), the presence of caregiver and having independent financial support for care. Additionally, any comorbidities were recorded in a free text field. This free text field was mined at the data analysis step to identify the most common comorbidities for assessment. These were diabetes mellitus, atrial fibrillation, previous stroke, coronary artery disease (CAD), smoking, dyslipidemia, CHF, hemiparesis, previous coronary bypass graft $(\mathrm{CABG})$, benign prostatic hypertrophy $(\mathrm{BPH})$ with urinary symptoms, chronic obstructive pulmonary disease, and obesity.

Patients were categorized as being either discharged home or to LTC, which we defined as any type of chronic care facility ranging from assisted living to higher level care where all activities of daily living and feeding are provided, as the dependent variable. Univariable logistic regression models were run for each of the independent variables to assess their relationship with the discharge destination. Correlation among the independent variables was assessed using Pearson and Spearman's correlation coefficients, where appropriate for variable types. Where pairs of variables were found to be highly correlated $(p>|0.8|)$, variables with higher recording consistency, or deemed more biologically plausible were retained for further modeling. Variables with a $p$-value of $<0.2$ were used to build a multivariable logistic model using a manual backwards selection approach, maintaining variables with a $p$-value of $\leq 0.05$. A priori rules for model building were set as follows: (1) a cut-off of $30 \%$ was used to assess confounding during the model building process, where variables that produced a $>30 \%$ change in other significant coefficients would be forced into the model. (2) Linear variables were visualized using locally weighted scatterplot smoothing with the log odds of the discharge destination in order to identify curvilinear relationships. Quadratic terms were introduced to the model where appropriate, or variables were categorized using logical groupings based upon cut-offs found in the literature. (3) Biologically significant interaction terms were assessed using a $p$-value cut-off of 0.05 .

Variables modeled as linear were age and change in Berg score from admission to discharge. Variables that were not well modeled in a linear manner and were therefore categorized were Berg scores at admission and discharge, categorized into $<20$, 20-<40, and 40+; and change in FIM was categorized to 1-4 and $5+$. These categorizations allowed for more appropriate modeling and to separate those with severe disabilities from those with less marked deficits. Additionally, location of stroke was modeled as categorical (left, right, and both hemispheres).

\section{Results}

Table 1 lists the variables, numbers of patients with data recorded for each variable, the odds ratios, and $p$-values for univariable analysis against the destination of being discharged to LTC or home. All of the ischemic strokes are involved in the cerebral hemispheres except one pontine stroke. We eliminated that case from our review. The following were significant predictors of LTC disposition: age, admission, and discharge FIM scores (allowing determination of improvement in scores, Figure 1), AlphaFIM score, change in AlphaFIM score, dependency and site of accommodation before the stroke (which are likely to be closely related), presence of a caregiver, urinary and bowel incontinence, the Berg Balance Scale score (Figure 2), MoCA, and ability to transfer. Interestingly, the following did not reach significance: sex, dysphagia, aphasia, hemianopsia, and various comorbidities (diabetes mellitus type 2, atrial fibrillation, previous stroke, CAD, CHF, smoking, dyslipidemia, hemiparesis, $\mathrm{BPH}$, and $\mathrm{CABG})$.

Multivariable analysis showed the following five factors to have the most prominent associations with LTC disposition: age, bowel incontinence, residence prior to stroke, laterality of the stroke, and caregiver availability (Table 2). Patients were more likely to be discharged to LTC if they were older, living outside of the home before the stroke, had a right hemisphere stroke, suffered from bowel incontinence, and had no caregiver available.

\section{Discussion}

Our study focused on those patients who were discharged from a rehabilitation unit after acute ischemic stroke and differs from some earlier studies that examined patients in stroke units. ${ }^{11,14-20}$ Thus, our study had a selection bias, usually 
Table 1: Univariable results for all predictor variables against the outcome of being discharged to LTC versus home

\begin{tabular}{|c|c|c|c|c|}
\hline Variable & & $N$ & Odds ratio & $p$-value \\
\hline Age & & 227 & 1.103 & $<0.001$ \\
\hline Average FIM admission score & & 227 & 0.423 & $<0.001$ \\
\hline AlphaFIM admission score & & 227 & 0.955 & $<0.001$ \\
\hline Average FIM at discharge & & 175 & 0.372 & $<0.001$ \\
\hline Delta Alpha & & 175 & 2.597 & 0.028 \\
\hline $\begin{array}{l}\text { Living outside of home before } \\
\text { stroke }\end{array}$ & & 227 & 6.500 & $<0.001$ \\
\hline $\begin{array}{l}\text { Dependent on others for activities } \\
\text { of daily life }\end{array}$ & & 227 & 2.596 & 0.019 \\
\hline \multirow[t]{3}{*}{ Hemisphere of stroke } & Both & \multirow[t]{3}{*}{201} & Referent & \multirow[t]{3}{*}{0.077} \\
\hline & Left & & 0.115 & \\
\hline & Right & & 0.436 & \\
\hline Bladder incontinence & & 205 & 5.068 & $<0.001$ \\
\hline Bowel incontinence & & 207 & 2.938 & 0.006 \\
\hline Dysphagia & & 199 & 1.409 & 0.322 \\
\hline Aphasia & & 212 & 1.585 & 0.177 \\
\hline \multirow[t]{3}{*}{ Berg at admission } & $<20$ & \multirow[t]{3}{*}{214} & Referent & \multirow[t]{3}{*}{0.002} \\
\hline & $20-40$ & & 0.406 & \\
\hline & $40+$ & & 0.171 & \\
\hline \multirow[t]{3}{*}{ Berg at discharge } & $<20$ & \multirow[t]{3}{*}{214} & Referent & \multirow[t]{3}{*}{$<0.001$} \\
\hline & $20-40$ & & 0.162 & \\
\hline & $40+$ & & 0.064 & \\
\hline \multirow[t]{3}{*}{ Delta Berg } & $<20$ & \multirow[t]{3}{*}{227} & Referent & \multirow[t]{3}{*}{0.828} \\
\hline & $20-40$ & & 0.893 & \\
\hline & $40+$ & & 1.280 & \\
\hline \multirow[t]{12}{*}{ Comorbidities } & T2DM & 227 & 0.208 & 0.133 \\
\hline & Atrial fibrillation & 227 & 1.617 & 0.267 \\
\hline & Previous cerebrovascular accident & 227 & 1.048 & 0.945 \\
\hline & CAD & 227 & 1.412 & 0.530 \\
\hline & Smoker & 227 & 0.273 & 0.038 \\
\hline & Dyslipidemia & 227 & 0.511 & 0.188 \\
\hline & $\mathrm{CHF}$ & 227 & 5.238 & 0.017 \\
\hline & Hemiparesis & 227 & 1.289 & 0.761 \\
\hline & CABG & 227 & 1.956 & 0.447 \\
\hline & $\mathrm{BPH}$ & 227 & 0.370 & 0.349 \\
\hline & COPD & 227 & 0.223 & 0.150 \\
\hline & Obesity & 227 & 0.370 & 0.349 \\
\hline Unable to transfer at admission & & 102 & Cannot converge & 0.004 \\
\hline Unable to transfer at discharge & & 139 & 6.769 & $<0.001$ \\
\hline MoCA score & & 91 & 0.827 & 0.001 \\
\hline Hemianopsia & & 190 & 1.809 & 0.166 \\
\hline No caregiver available & & 208 & 8.772 & $<0.001$ \\
\hline $\begin{array}{l}\text { Financial challenges/insurance not } \\
\text { available }\end{array}$ & & 220 & 3.125 & 0.100 \\
\hline
\end{tabular}

A fib, atrial fibrillation; $\mathrm{BPH}$, benign prostatic hyperplasia; $\mathrm{CABG}$, previous coronary bypass graft; $\mathrm{CAD}$, coronary artery disease; $\mathrm{CHF}$, congestive heart failure; COPD, chronic obstructive pulmonary disease; Delta Alpha, difference in AlphaFIM score between admission and discharge; Delta Berg, change in Berg score between admission and discharge; FIM, functional independence measure; MoCA, Montreal Cognitive Assessment score; T2DM, type 2 diabetes mellitus. 


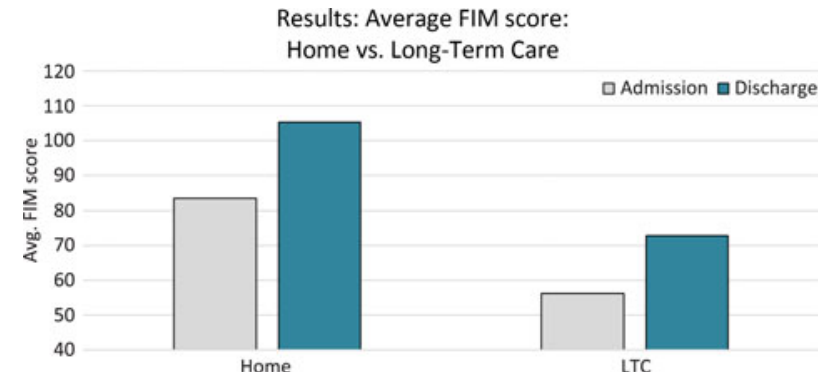

Figure 1: Average FIM score at admission and discharge for ischemic stroke patients discharged to home and LTC from the rehabilitation unit at Grey Bruce Health Services in Owen Sound, Ontario, between January 1, 2005 and December 31, 2015.

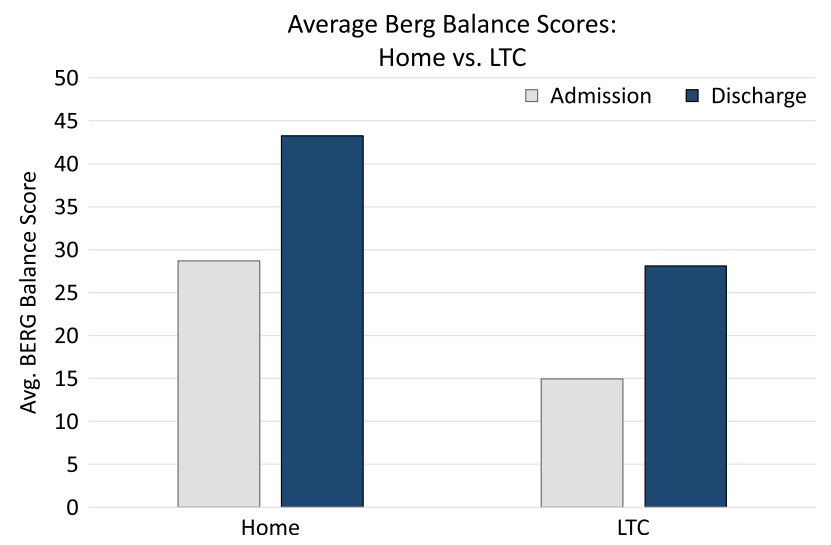

Figure 2: Average Berg Balance Scores at admission and discharge for ischemic stroke patients discharged to home and LTC from the rehabilitation unit at Grey Bruce Health Services in Owen Sound, Ontario, between January 1, 2005 and December 31, 2015.

eliminating those patients with early mortality and AlphaFIM scores $>80$ and $<40$ (criteria for admission to rehabilitation after 2014). Our study was more inclusive of more independent variables than many earlier studies with respect to discharge destination from rehabilitation after acute ischemic stroke.

We found discharge destination to be associated with numerous variables at the univariable level: Berg balance score, indicating risk of falling (recently shown by Louie and $\mathrm{Eng}^{21}$ as a strong predictor of regaining unassisted ambulation), age (as shown previously by Scrutinio et al., Glader et al., and Bindawas et al.), ${ }^{3,18,22}$ FIM score and improvement in FIM score during the stay on rehabilitation (as shown by Scrutinio et al. and Thorpe et al.), ${ }^{3,23}$ bladder and bowel incontinence (bladder incontinence was also shown to be related to LTC discharge by John et al.), ${ }^{15}$ ability to transfer (not previously explored), and MoCA score (as shown by Chan et al.). ${ }^{24}$ The self-perceived functional improvement, dependency for indoor functioning and social relations with family members/caregivers are also determinants in participation and eventual autonomy, ${ }^{25}$ but this was not examined in our study.

Not surprisingly, patients who were already in LTC prior to their stroke would be unlikely to go home after a stroke, which would produce even greater disability. Similarly, the presence of a caregiver already in place would greatly enhance the chances of being discharged home, as others have shown. ${ }^{14,20,26}$ Some variables are inter-related, for example, younger patients are more likely to have a caregiver at home than older patients. ${ }^{14}$ It is of interest that comorbidities were not statistically associated with discharge destination. Some neurological deficits, for example, hemianopsia, aphasia, dysphagia also did not impact on discharge destination, as was shown by Dromerick and Reding, ${ }^{19}$ even though they may pose serious social and care challenges. ${ }^{27}$ However, multiple, coexisting comorbidities at least in acute settings, can affect disposition. ${ }^{19,28}$ This is especially important in the elderly, where treatment of acute complications can make a difference in outcome. ${ }^{29}$

Our study had similar results to the larger Canadian Institute of Health Information (CIHI) study published in $2009 .{ }^{30}$ Motor function on admission was the strongest predictor of discharge destination, followed by whether or not the patient lived with someone prior to the stroke. There were some differences between our study and the CIHI report, in that all types of hemorrhagic strokes were included and comorbidities, continence, and Berg scores were not specifically included in the CIHI study. More detail was paid in the CIHI study to cognitive factors. A recent meta-analysis ${ }^{31}$ confirmed the importance of stroke severity and age as strong predictors of discharge to LTC. There was considerable heterogeneity among the 18 included papers, which were not comprehensive in including all possible variables; potentially modifiable (risk) factors were rarely examined.

Multivariable analysis revealed the five main variables that together were best able to predict the discharge destination: age, residence prior to stroke, right hemisphere site of stroke, bowel continence, and presence of caregiver. While increasing age, bowel incontinence, and the absence of a caregiver are logically expected to be linked to discharge to LTC (and were found to be statistically linked in our study), our finding that right hemispheric stroke patients are more likely to go to LTC than those with left or bilateral hemispheric strokes seems at odds with earlier papers. ${ }^{32}$ Prior research has suggested that left hemispheric strokes do worse than right hemispheric strokes, but these studies related to those with acute strokes: patients with left-middle cerebral artery strokes were more likely to show early mortality and an initially lower Glasgow Coma Scale score and higher National Institutes of Health Stroke Scale (NIHSS). ${ }^{32}$ However, the selective nature of our study eliminates these early differences and produces a more "even playing field". Thus, a more direct comparison of right versus left hemispheric damage in the post-acute phase was possible.

Enduring unilateral spatial neglect (USN) is defined as "failure to report, respond, or orient to novel or meaningful stimuli presented to the side opposite the brain lesion when this failure cannot be attributed to either sensory or motor deficits." ${ }^{33}$ While the hospital charts did not consistently mention USN, this is a feature of right hemisphere lesions, in contrast with left hemisphere lesions that have more language-related deficits. ${ }^{34-37}$ Patients with USN do not improve as much in motor or sensory function or activities of daily living during the period of acute hospitalization and rehabilitation as those without USN, in comparison with those patients with hemiparesis but without neglect. ${ }^{34,38}$ Thus, those right hemisphere-damaged patients with neglect tend to show less improvement and would probably be more likely to require LTC. ${ }^{39}$ Most patients (87\%) with right hemisphere strokes showed USN in the series of Klinke et al. ${ }^{39}$ The relative lack of improvement during rehabilitation in right hemisphere damaged (RHD) compared to left hemisphere damaged (LHD) stroke patients was also 
Table 2: Multivariable results for logistic regression analyses of predictors associated with being discharged to LTC

\begin{tabular}{l|c|c|r}
\hline Variable & Odds ratio & Standard error & $p$-value \\
\hline Age & 1.154 & 0.042 & $<.001$ \\
\hline Living outside of home before stroke & 14.474 & \multicolumn{2}{l}{} \\
\hline Hemisphere of stroke & \multicolumn{4}{|l}{} \\
\hline Both & Referent & 0.17 .156 & \\
\hline Left & 0.057 & 0.113 & \\
\hline Right & 0.307 & 0.608 & 0.014 \\
\hline Bowel incontinence & 10.569 & 7.955 & 0.002 \\
\hline No caregiver available & 22.073 & $<0.001$ & \\
\hline
\end{tabular}

noted by Ween et al. ${ }^{9}$ We suggest that neglect and other deficits should be further explored with advanced techniques, such as fMRI, to explore how brain networks are affected and ultimately therapy can be targeted accordingly. ${ }^{40}$

While lower MoCA scores increase the probability of LTC destination, this may apply primarily to left hemispheric strokes. It has been shown that the MoCA lacks sensitivity and specificity in the detection of overall cognitive deficiency, processing speed, executive functions, and nonverbal memory for patients with right hemisphere strokes compared with those with left hemispheric strokes, when patients were assessed with comprehensive neuropsychological testing. ${ }^{27}$ This could create a problem in designing rehabilitative strategies for patients with right hemispheric strokes when MoCA is used as the main cognitive screening tool. It is noteworthy that MoCA scores were similar in discharge destination from acute stroke units in the study by Dutrieux et al. ${ }^{14}$ More in-depth cognitive assessment indicates that visuospatial, executive function, memory, and language function were the most important vascular cognitive impairments in determining functional outcomes. ${ }^{41}$ Also, pre-stroke dementia did not alter the functional outcome of elderly patients with ischemic stroke; both the demented and nondemented groups (using MoCA scoring criteria) made similar motor gains on FIM scoring. ${ }^{17}$ Similarly, the NIHSS has been shown to be more predictive of outcome for LHD than RHD ischemic strokes. ${ }^{42}$

We found no significant differences between men and women for discharge to LTC. Other studies had variable results, some showing that men were more likely to require institutional care than women or that there were no sex differences in disposition. ${ }^{43-46}$ The largest study, involving thousands of patients in the Swedish stroke registry found women fared worse than men, but women had more unfavorable predisposing factors. ${ }^{18}$ It is possible that our study was underpowered to show a sex difference. This may be worth examining in a larger, future study, as there may be gender differences in ability to cope independently or in the availability of a spouse being available to act as caregiver.

Our study has several other limitations. These largely relate to its selection bias and retrospective nature, prone to have missing data, and imprecision for localization and classification of stroke. Some data were missing in our retrospective review, although our calculations took this into account. From the review of charts and neuro-imaging (mainly CT images) it was not always possible to separate small vessel/lacunar strokes from larger vessel or cardioembolic strokes. Most of our cases were large vessel rather than lacunar strokes; only three were obviously lacunar in nature and none were recognized as brainstem infarcts. While our study is not representative of the case mix of patients admitted for stroke rehabilitation in most centres, the severity of strokes as measured by preadmission AlphaFIM and FIM scores during rehabilitation is probably similar. As Ween et al. ${ }^{9}$ pointed out the lesion site and lesion type (large vessel versus small vessel strokes) may have confounding effects on discharge destination, having predominantly large vessel ischemic strokes in our series allows for a more direct comparison of lesion site.

The probability of discharge home versus LTC is best understood by considering multiple variables, as in our study. ${ }^{47,48}$ Using grouped data to make decisions about individual patient discharge destination has limitations. Among individual cases, there will be different weightings of variables dependent on caregivers, affect, motivation, and other factors that require individual consideration. ${ }^{49}$ This is not to deny that any improvement gained in rehabilitation (Figures 1 and 2) and continued outreach care is worth the effort in many patients destined for LTC, as the subsequent level of care required, resource implications, and quality of life can benefit from the gains made in rehabilitation. Attention should be given to the modifiable risk factors that respond to the rehabilitative effort. Clearly, more work is needed to model the variables in cluster ${ }^{50,51}$ or multivariable analysis in a larger sample size, preferably in a prospective study, ${ }^{51}$ for timely, projected effects of rehabilitation strategies on patients with ischemic strokes on the full spectrum of outcomes. ${ }^{52}$ While such population studies will help us to pay more attention to modifiable variables, each patient requires individual attention, as the importance or weighting of the various factors will vary with each case.

\section{Statement of Authorship}

Each author contributed to the design and authorship of the article. AS collected and tabulated the data; SG-K performed the statistical analysis; and GBY performed literature searches and contributed to the discussion.

\section{Disclosures}

The authors declare no conflicts of interest. 


\section{REFERENCES}

1. Kruger and Associates. Estimated prevalence of disability in stroke survivors with disability in Canada. Canadianstoke.ca, 2015.

2. Andersen KK, Olsen TS, Dehlendorff C, Kanmesgaard LP. Hemorrhagic and ischemic strokes compared: stroke severity, mortality and risk factors. Stroke. 2009;40:2068-972.

3. Scrutinio D, Monitollo V, Guido P, et al. Functional gain after inpatient stroke rehabilitation correlates and impact on long-term survival. Stroke. 2015;46:2976-80.

4. Jörgensen HS, Nakayama H, Raaschou HO, Larsen K, Hübbe P, Olsen TS. The effect of a stroke unit: reduction in mortality, discharge rate to a nursing home, length of hospital stay and cost. A community-based study. Stroke. 1995;26:1178-82.

5. Kalra L. The influence of stroke unit rehabilitation on functional recovery from stroke. Stroke. 1994;25:821-5.

6. Kaste M, Palomäki H, Sarma S. Where and how should elderly stroke patients be treated? A randomized trial. Stroke. 1995;26:249-53.

7. Dam M, Tonin P, Casson S, et al. The effects of long-term rehabilitation therapy on post-stroke hemiplegic patients. Stroke. 1994;24:1186-91.

8. Rollnik JD, Bertram M, Bucka C, et al. Criterion validity and sensitivity to change of the Early Rehabilitation Index (ERI): results from a German multi-center study. BMC Res Notes. 2016;9:356.

9. Ween JE, Alexander MP, D'Esposito M, Roberts M. Factors predictive of stroke outcome in a rehabilitation setting. Neurology. 1996;47:388-92.

10. Ring H, Feder M, Schwartz J, Samuels G. Functional measures of first-stroke rehabilitation inpatients: usefulness of the functional independence measure total score with clinical rationale. Arch Phys Med Rehabil. 1997;78:630-5.

11. Hakkennes SJ, Brock K, Hill KD. Selection of patients for inpatient rehabilitation after acute stroke: a systematic review of the literature. Arch Phys Med Rehabil. 2011;92:2057-70.

12. Rayegani SM, Raeissadat SA, Alikhani E, Bayat M, Bahrami MH, Karimzadeh A. Evaluation of complete functional status of patients with stroke by functional independence measure scale on admission, discharge and six months poststroke. Iran J Neurol. 2016;15:202-8.

13. Andersen KK, Olsen TS, Dehlendorff C, Kammersgaard LP. Hemorrhagic and ischemic strokes compared: stroke severity, mortality, and risk factors. Stroke. 2009;40:2068-72.

14. Dutrieux RD, van Eijk M, Marloes ML, van Heugen CM, VisserMeily JMA, Achterberg WP. Discharge home after acute stroke: differences between older and younger patients. J Rehabil Med. 2016;48:14-8.

15. John G, Bardini C, Mégevand P, Combescure C, Dallenbach P. Urinary incontinence as a predictor or death after new-onset stroke: a meta-analysis. Eur J Neurol. 2016;23:1548-55.

16. Shah BR, Khan NA, O'Donnell MJ, Kapral MK. Impact of language barriers on stroke care and outcomes. Stroke. 2003;46:813-8.

17. Mizrahi E-H, Arad M, Adunsky A. Pre-stroke dementia does not affect the post-acute care functional outcome of old patients with ischemic stroke. Geriatr Gerontol. 2015;16:928-33.

18. Glader E-L, Stegmayr B, Terént A, Huter-Åsberg K, Wester P-O, Asplund K. Sex differences in management and outcome after stroke. Stroke. 2003;34:1970-5.

19. Dromerick AW, Reding MJ. Functional outcome for patients with hemiparesis, hemihypestheia and hemianopsia. Stroke. 1995;26:2023-6.

20. Mirkowski M, McClure A, Speechly M, Teasell R. Caregiver availability for severe stroke results in improved functional ability at discharge from inpatient rehabilitation. Disability Rehabil. 2018;40:457-61.

21. Louie DR, Eng JJ. Berg balance scale score at admission can predict walking suitable for community ambulation at discharge from inpatient stroke rehabilitation. J Rehabil Med. 2017;50:37-44.

22. Bindawas SM, Vennu V, Mawajdeh H, Alhaidary H. Functional outcomes by age after inpatient rehabilitation in Saudi Arabia. Clin Interv Aging. 2017;12:1791-7.

23. Thorpe ER, Garrett KB, Smith AM, Reneker JC, Phillips RS. Outcome measure scores predict discharge destination in patients with acute and subacute stroke. J Neurol Phys Ther. 2018;42:2-11.
24. Chan E, Altendorf S, Healy C, Werring DJ, Cippolotti L. The test accuracy of the Montreal Cognitive Assessment (MoCA) by stroke lateralization. J Neurol Sci. 2016;373:100-4.

25. Törnbom K, Hadartz K, Sunnerhagen KS. Self-perceived participation and autonomy at 1-year post-stroke: a part of the Stroke Arm Longitudinal Study at the University of Gothenburg (SALGOT Study). J Stroke Cerebrovasc Dis. 2018;27: 1115-22.

26. Pereira S, Foley N, Salter K, et al. Discharge destination of individuals with severe stroke undergoing rehabilitation: a predictive model. Disability Rehabil. 2014;36:727-31.

27. Wray F, Clarke D. Longer-term needs of stroke survivors with communication difficulties living in the community: a systematic review and thematic synthesis of qualitative studies. BMJ Open. 2017;7:e017944.

28. Dutta D, Thornton D, Bowen E. Using population-based routinely collected data from the Sentinel Stroke National Audit Programme to investigate factors associated with discharge to care home after rehabilitation. Clin Rehabil. 2017;32:1108-18.

29. Kim BR, Lee J, Sohn MK, et al. Risk factors and functional impact of medical complications of stroke. Enn Rehabil Med. 2017;41:753-60.

30. Canadian Institute of Health Information. Factors predicting discharge from home from inpatient rehabilitation after stroke, May 5, 2009, pp. 1-18.

31. Burton JK, Ferguson EEC, Barugh AJ, et al. Predicting discharge to long term care after stroke. J Am Geriatr Soc. 2017;66:161-9.

32. Hedna VS, Bodhit AN, Ansan S, et al. Hemispheric differences in ischemic stroke: is left hemisphere stroke more common? J Clin Neurol. 2013:9:97-102.

33. Heilman KM, Watson RT, Valenstein E. Neglect and related disorders. In: Heilman KM, Valenstein E, editors. Clinical neuropsychology, 3rd ed. New York: Oxford University Press; 1993, pp. 279-336.

34. Katz N, Hartneb-Maeir A, Ring H, Soroker N. Functional disability and rehabilitation outcome in right hemisphere damaged patients with and without spatial neglect. Arch Phys Med Rehabil. 1999;80:379-84.

35. Stone SP, Wilson B, Wroot A, et al. The assessment of visuospatial neglect after acute stroke. J Neurol Neurosurg Psychiatry. 1991;54:345-50.

36. Robertson IH. The relationship between lateralized and nonlateralized attentional deficits in unilateral neglect. In: Robertson IH, Marshall JC, editors. Unilateral neglect: clinical and experimental studies. Hillside,NJ: Lawrence Erlbaum Publishers; 1993, pp. 63-86.

37. Zoccolotti P, Antonucci G, Judica A, Monenero P, Pizzamiglio L, Razzano C. Incidence and evolution of the hemineglect disorder in chronic patients with unilateral right brain damage. Int $\mathrm{J}$ Neurosci. 1989;47:209-16.

38. Spaccavento S, Cellamare F, Falcone R, Loverre A, Nardilli R. Effect of subtypes of neglect on functional outcome in stroke patients. Ann Phys Rehabil Med. 2017;60:376-381.

39. Klinke ME, Hjaltoson H, Berg G, Tryggvadóttirt H, Jónsdóttirt H. Hemispatial neglect following right hemisphere stroke: clinical course and sensitivity of diagnostic tests. Top. Stroke Rehab. 2017;25:120-30.

40. Riestra AR, Barrett AM. Rehabilitation of spatial neglect. Handb Clin Neurol. 2013;110:346-55.

41. Park SH, Sohn MK, Jee S, Yang SS. The characteristics of cognitive impairment and their effects on functional outcome after inpatient rehabilitation in subacute stroke patients. Ann Rehabil Med. 2017;42:734-42.

42. Yoo AJ, Romero J, Nogueiro RG, et al. Predictors of functional outcome vary by the hemisphere of involvement in major ischemic stroke treated with intra-arterial therapy: a retrospective cohort study. BMC Neurol. 2010;10:25.

43. Holroyd-Leduc JM, Kapral MK, Austin PC, Tu JV. Sex differences and similarities in the management and outcome of stroke patients. Stroke. 2000;31(8):1833-7.

44. Lai SM, Alter M, Friday G, Lai SL, Sobel E. Disposition after acute stroke: who is not sent home from hospital? Neuroepidemiology. 1998;17:21-9. 
45. Appelros P, Nydevik I, Viitanen M. Poor outcome after first-ever stroke: predictors for death, dependency, and recurrent stroke within the first year. Stroke. 2003;34:122-6.

46. Sharma JC, Fletcher S, Vassallo M. Characteristics and mortality of acute stroke patients: are there any gender differences? J Gender Specific Med. 2002;5:24-7.

47. Everink IH, van Haastregt JC, van Hoof SJ, Schols JM, Kempen GI. Factors influencing home discharge after inpatient rehabilitation of older patients: a systematic review. BMC Geriart. 2016;16:5.

48. Itaya T, Murakami Y, Nomura E, Fukushima T, Nishigaki M. Assessment model to identify patients with stroke with a high possibility of discharge to home: a retrospective cohort study. Stroke. 2017;48:2812-8.
49. Nelson MLA, Hanna E, Hall S, Calvert M. What makes stroke rehabilitation patients complex? Clinician perspectives and the role of discharge pressure. J Comorb. 2016;6:35-41.

50. Simpson AN, Wilmskoetter J, Hong I, et al. Stroke administrative severity index: using administrative data for 30-day poststroke outcomes prediction. J Comp Eff Res. 2017;7:293-304.

51. Duncan PW, Bushnell CD, Rosamond WD, et al. The comprehensive post-acute Stroke services (COMPASS) study: design and methods for a cluster-randomized trial. BMC Neurol. 2017; 17(1):133.

52. Cameron JI, O'Connell C, Foley N, et al. Canadian stroke best practice recommendations: managing transitions following stroke, guidelines update 2016. Int J Stroke. 2016;11:807-822. 